\title{
FRACTURE PREDICTION FOR ELEMENTS WITH SHARP INCLUSIONS
}

\author{
Grzegorz Mieczkowski \\ Bialystok University of Technology, Poland \\ g.mieczkowski@pb.edu.pl
}

\begin{abstract}
The article is related to the prediction of fracture toughness of materials with sharp inclusions. Such materials include particle-reinforced composites, which are currently used on a wide scale in many areas of the economy. Matrix and reinforcement components selected in the right proportions, when combined with each other, ensure better material usability (e.g. hardness, resistance to abrasive wear, high-temperature work capability). However, in these types of materials there is forced compatibility of displacements on an interface of components with different stiffness. This can cause that cracks occur at the interface. What is more, the reinforcement particles often have sharp corners. This results in the fact that stress fields with large gradients are generated in the corner/crack tip region, which consequently initiates fracture of the material. A criterion based on the Theory of Critical Distances (TCD) is often used to predict the fracture toughness of homogeneous materials. In the presented work the possibility of applying this theory for materials with inclusions was examined. The experimental verification of the analysed fracture criterion required the performance of the necessary experimental tests aimed at determining critical loads. Experimental tests were carried out on specially prepared specimens (homogenous material containing a sharp inclusion with single lateral crack) made of steel (inclusion) and PMMA (matrix), subjected to a tensile load. Values of critical loads and crack propagation directions were compared with the predicted values obtained from TDC. Based on the tests performed, it was found that the TDC method can be used to predict fractures of materials with inclusions, but some modifications are required.
\end{abstract}

Keywords: fracture criterion, composite materials.

\section{Introduction}

Currently, composite materials are used on a large- scale in machine, aerospace or building constructions. The homogeneous components selected in the right proportions, when combined with each other, provide greater stiffness and strength at a lower weight. In addition, particle or dispersion strengthened composites have better utility features, such as hardness, wear resistance or possibility to work at higher temperatures.

Composites are characterized by macroscopic heterogeneity of the structure. There is forced compatibility of displacements on an interface of components with different rigidity and the potential presence of material discontinuities, or sharp corners, causing local large stress gradients. Such concentrators can generate singular stress fields with qualitatively different features than in the case of defects located in a homogeneous material [1-9]. The resulting stress fields can be characterized by singularities described both real and complex eigenvalue. These factors cause difficulties related to the estimation of durability and strength of construction parts made of this type of material, especially in cases when interfacial cracks occur (analytical solutions are difficult to obtain). Fracture criteria based on the theory of critical distances (TCD) [10-12] or Strain Energy Density (SED) [13] may be useful in such problems - the use of them does not require knowledge of the analytical description of stress fields occurring in the sharp corners tip area. The use of such an approach has been positively verified, e.g. for notches located in homogeneous materials [14-17] or in bi-materials [18].

In literature, scientific research related to the use of TDC for the prediction of fracture toughness of homogeneous materials containing inclusions with sharp corners can rarely be found. Therefore, the main objective of the presented work is to experimentally verify, for homogeneous materials with inclusions, the fracture criterion based on the classical and modified TDC concept.

In addition, in the area of interest of the author was also a comparison of strength of parts made of a homogeneous material, in which local stress gradient is generated respectively by inclusions and notches with the same tip angles. For this reason, additional strength analyses were performed for notched elements (with identical geometrical features as inclusions).

\section{Materials and methods}

The idea of the used criterion is described in the first subsection of the section. The experimental verification of the analysed fracture criteria required to perform experimental and numerical 
investigations. The description of experimental test procedures and specimens is presented in subsection 2. The third subsection discusses numerical modelling carried out using the finite element method (FEM).

\section{The theory of critical distances}

At the outset, it should be emphasized that TDC is not one method, but a group of methods [10] that have one thing in common. This common feature is a parameter called a critical distance. The critical distance can specify:

- the distance from the defect tip to the point, in which stresses in the material are determinedpoint method (PM);

- the length of the section on which the stresses occurring in the tip area of the defect are averaged - linear method (LM) ;

- the characteristic dimension of the plane figure on which surface the stresses in the material are averaged - surface method (AM) ;

- the characteristic dimension of the solid body inside which the stresses are averaged - the volume method (VM).

The choice of the method (PM, LM, AM, VM) depends on the type of the defect, material or load conditions. What is more, in literature, the PM method is often classified as a local criterion, while the remaining methods are classified as non-local criteria.

When estimating the fracture toughness of the material using TDC techniques, the stress (assigned to the critical distance) is compared with the critical one. In the prediction process, the classical [1921] or the modified [9; 22-24] TDC concept can be used. Modifications of the classical approach generally rely on various interpretations of the critical distance, critical stress and the stress which is assigned to the critical distance (what is described in more detail further in this section).

Despite the fact that TDC concept has been known for over 50 years, it still attracts special interest from engineers. The reason for this is the development of numerical methods, e.g. FEM [25], which allow to easily determining the stresses in the tip area of material defects, such as sharp corners, inclusions, etc. Numerical analyses eliminate the necessity of applying analytical solutions (description of stress fields). Moreover, such analyses can be performed for any load conditions (static, dynamic) and take into account (together with experimental research) piezoelectric, frictional and flow aspects [26-35].

In this paper, for the prediction of fracture toughness (estimation of critical loads at which damage of specimens can be expected) both the classic and modified approach are used, what is described below.

\subsection{Classic approach - linear method LM}

In the classic LM it is assumed that the crack initiation process takes place, when the principal stress $\sigma_{I}$, averaged over the distance $2 L$, reaches (Fig.1) the critical value $\sigma_{o}$ called inherent strength:

$$
\frac{1}{2 L} \int_{0}^{2 L} \sigma_{I}(r) d r=\sigma_{o} .
$$

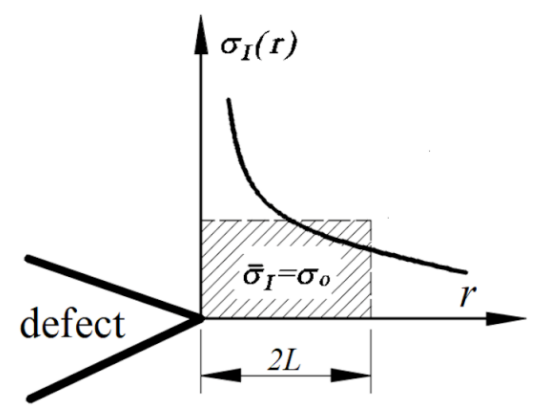

Fig. 1. Graphical interpretation of the point method criterion (LM) 
Typically, it is assumed that the direction of the critical distance is perpendicular to the direction of the principal stresses. Both $L$ and $\sigma_{o}$ are treated as material constants. Methods of their determination have been discussed, e.g. in $[24 ; 36]$.

It should be emphasized that the critical stress, with the exception of ceramics, is different from the tensile strength $\sigma_{u}$ (usually $\sigma_{u}<\sigma_{o}$ ). It is, however, worth mentioning that the classic approach is recommended for blunt notches problems. For elements with sharp defects, modified approaches, based on Linear Elastic Fracture Mechanics (LEFM ), are rather used.

\subsection{Linear Elastic Fracture Mechanics approach}

The criterion often used, based on LEFM, is the criterion proposed by Novozilow [37]. In this criterion it is assumed that the fracture process will occur, when the hoop stress $\sigma_{\varphi}$ averaged over a certain distance reaches a critical value (equal to the tensile strength $\sigma_{u}$ ), causing decoherence of the material (Fig. 2). This condition can be written as follows:

$$
\frac{1}{d_{0}} \int_{0}^{d_{0}} \sigma_{\varphi}\left(\rho_{c}, \varphi_{0}\right) d r=\sigma_{u} \text {. }
$$

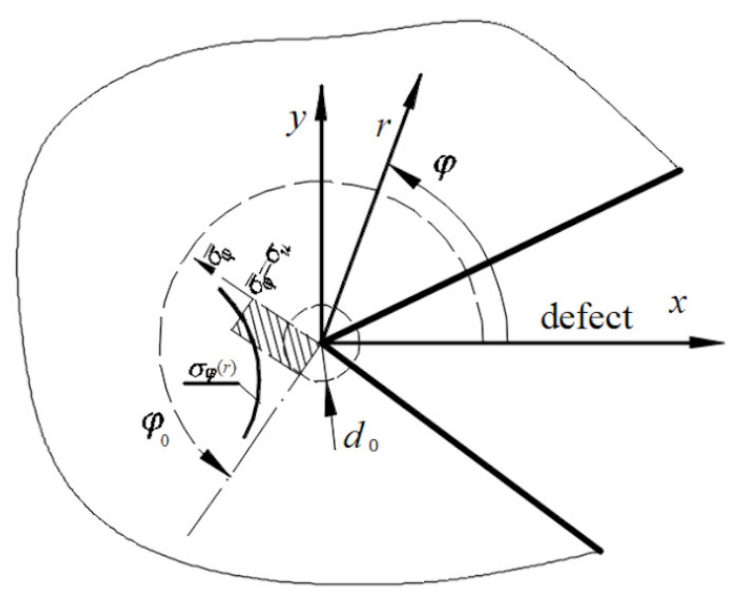

Fig. 2. Graphical interpretation of the Novozhilov's fracture criterion

The discussed criterion, apart from determining critical load values, allows determining the propagation direction $\left(\varphi_{o}\right)$, which corresponds to the maximum value of averaged hoop stresses. The value of the parameter $d_{0}$ determining the length of the critical distance can be determined from wellknown fracture criteria, e.g. the Griffith-Irwin criterion:

$$
\frac{1}{d_{0}} \int_{0}^{d_{0}} \frac{K_{I c}}{\sqrt{2 \pi r}} d r=\sigma_{u} .
$$

By transforming formula (3) one obtains:

$$
d_{0}=\frac{1}{2 \pi}\left(\frac{2 K_{I c}}{\sigma_{c}}\right)^{2},
$$

where $K_{I c}-$ fracture toughness of a material.

\section{Experimental investigations}

\subsection{Materials and test specimens}

The experimental tests carried out were intended for determining the critical loads (forces at which damage of specimens is achieved) and the fracture toughness of a material $\left(K_{I c}\right)$. Three types of specimens were used: with sharp inclusions, notched and cracked. The method of preparation of the 
specimens used in the tests (along with their geometric and material characteristics) is described below.

\section{a) Specimens with sharp inclusions}

Specimens composed of two parts with different mechanical properties were made. First, symmetric sharp notches with tip angles $60^{\circ}$ and $90^{\circ}$ were cut in PMMA (Poly(methyl methacrylate)), and then a matching element made of S235JR steel was glued into the cut-out space. So as to ensure the formation of cracks on the bottom surface along the inclusions, only the upper surfaces of both parts (thick line in Figure 2a) were adhesively bonded together (Loctite 401 adhesive). The adhesive has been selected so that its stiffness properties are similar to those of PMMA. Therefore, it was possible to confirm the assumption that the homogeneous material with inclusions is modelled, rather than the three-layer composite material.

\section{b) Notched specimens}

Double edge notched specimens (with the tip angles of $60^{\circ}$ and $90^{\circ}$ ) were made of PMMA, as shown in Figure 3c. The shapes and depths of notches are the same as those for specimens with inclusions. The specimens were used to compare the influence of various defects (notch/inclusions), with identical geometry, on the strength of the material in which these defects are located.

\section{c) Cracked specimens}

The specimens were prepared by mechanical incision of two symmetrical edge cracks with a length of $22 \mathrm{~mm}$. The specimens were used to determine the fracture toughness of PMMA (due to the thickness of the used specimens, literature data could not be assumed).

a)

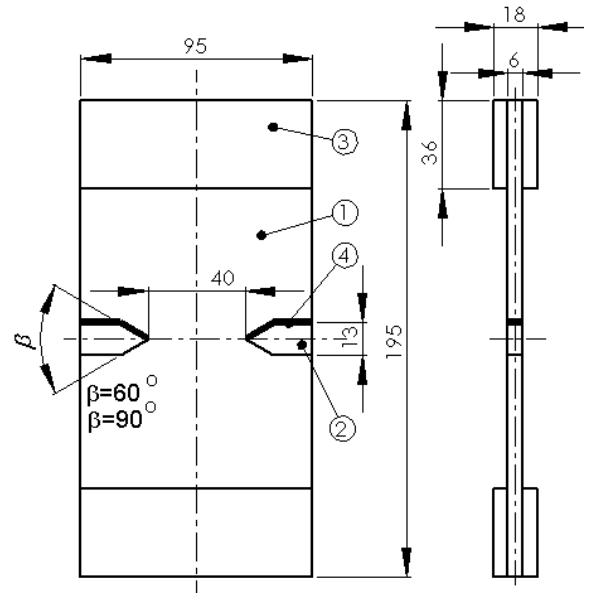

b)

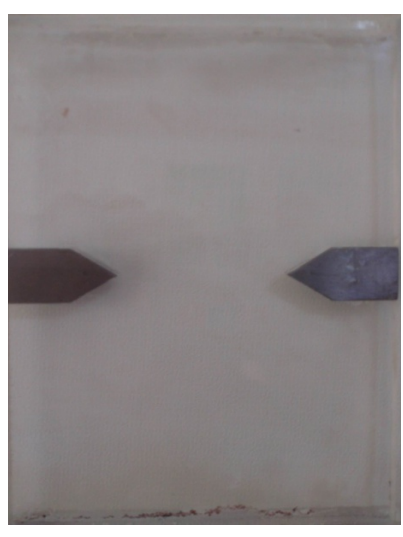

c)

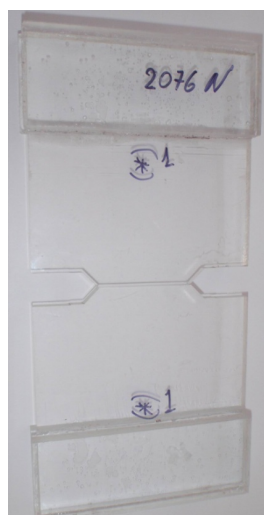

Fig. 3. Test specimens: a - geometrical features $(1$ - S235JR1, 2 - PMMA, 3 - overlays, 4 - adhesive layer); $\mathrm{b}^{\circ}$ specimen with inclusions; $\mathrm{c}$ - notched specimen (after damage)

Table 1 lists the values of material properties of the materials of which the specimens are made.

Table 1

Values of Young's modulus and Poisson's ratios for steel S235JR and PMMA

\begin{tabular}{|l|c|c|}
\hline Steel & Young's modulus, MPa & Poisson's ratio \\
\hline S235JR & $2.1 * 105$ & 0.3 \\
\hline PMMA & $3.3 * 103$ & 0.3 \\
\hline
\end{tabular}

\subsection{Test procedures}

The tests were carried out on the INSTRON 8502 strength machine, enabling the registration of the loading force $F$ in the function of the displacement of the work handled. The values of the critical load $F_{c}$ were determined on the basis of the force vs. displacement graph $-F(d)$. The critical load was the value of the force corresponding to the load recorded at the moment when the graph $F(d)$ showed a sudden increase in displacements with a simultaneous decrease in the force $F$.

As already mentioned, cracked specimens, for which the critical loads $F_{c}$ were experimentally determined, were used to determine the fracture toughness. Based on the critical loads and using the formula (18) [38], the fracture toughness was determined. 


$$
K_{I c}=\sigma \sqrt{\pi a}\left(1+0.122 \cos ^{4}\left[\frac{\pi \omega}{2}\right]\right) \sqrt{2 \tan \left[\frac{\pi \omega}{2}\right] /(\pi \omega)},
$$

where $\sigma=F_{c} /(w g), \omega=2 a / w, w=95 \mathrm{~mm}, g=5 \mathrm{~mm}, a=22 \mathrm{~mm}$.

\section{FEM modelling}

The test specimens were modelled by FEM using the ANSYS environment. The specimen geometry and material properties were identical to those used in the experimental studies (described in section 3). Figure 5 shows the division into finite elements and boundary conditions of arbitrarily selected samples. Because of the symmetries, only halves of the specimens were numerically modelled.

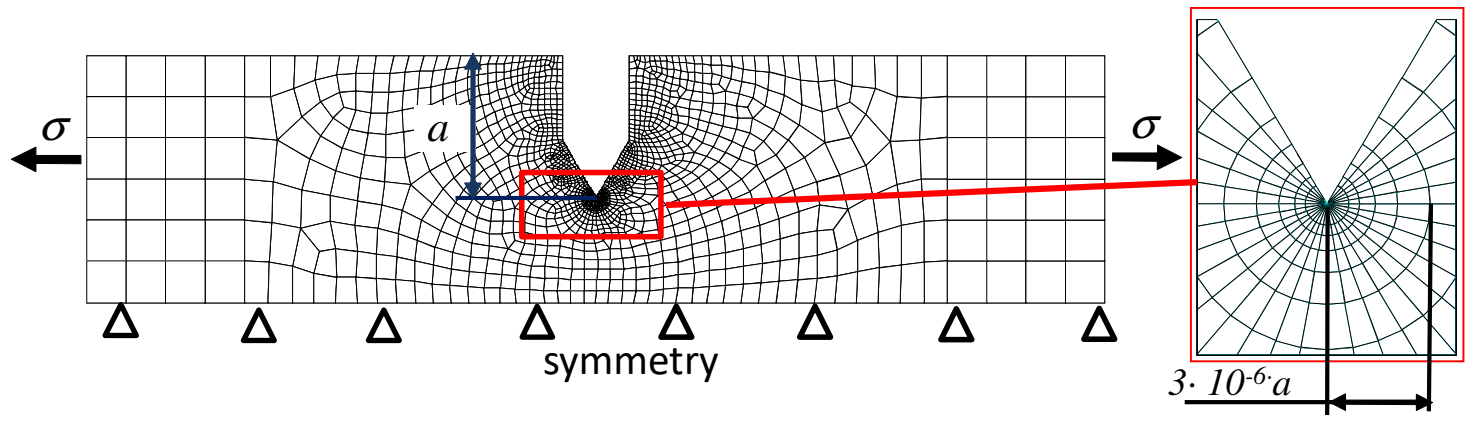

Fig. 5. Boundary conditions and division into finite elements of notched specimens with tip angle $\beta=60^{\circ}$

Plane specimens were described with quadrangle, eight-node finite elements with increased refinement (according to the arithmetic series) in the tip area, with triangular degenerated elements surrounding a singular point.

The left edge of the samples is extensioned with the load $\sigma=1 \mathrm{MPa}$, and the right one slidably supported. As regards support conditions of the lower edge, symmetry conditions are set on it. As for the modelling of specimens with inclusions, as already mentioned, they can be treated as a homogeneous material with sharp inclusion. Therefore, the adhesive layer was not included in the prepared numerical models. As for the connection conditions of individual components, the nodes lying at the interface were shared between both materials. There was not allowed slip between components on the interface. The numerical calculations are carried out for the plane stress state.

Numerical tests were aimed at determining the stresses, which are necessary for prediction with the use of chosen fracture criteria.

\section{Results and discussion}

In the experimental tests, for individual types of specimens, the values of critical forces $F_{c}$ (Table 2 ) and directions of crack propagation $\varphi_{0}$ were determined. The fracture process, as could be expected, was initiated at the tip of inclusions/notches. Cracks propagated in PMMA. The crack propagation directions were always perpendicular to the direction of stress $\sigma$ (Fig.5). Thus, according to Figure 2, the propagation directions $\varphi_{0}$ were always equal to $180^{\circ}$.

To test selected strength hypotheses, it was necessary to determine the material parameters. As the crack propagation took place in PMMA, these parameters were determined (own studies and literature data) for this material, and their values are presented in Table 2.

Table 2

Strength parameters used in the tested hypotheses

\begin{tabular}{|l|l|}
\hline Parameter & PMMA \\
\hline$\sigma_{\mathrm{o}}, \mathrm{MPa}$ & $136[36]$ \\
\hline$L, \mathrm{~mm}$ & $0.06[36]$ \\
\hline$K_{\mathrm{Ic}}, \mathrm{Mpa} \cdot \mathrm{mm}^{1 / 2}$ & $33.14(5)$ \\
\hline$\sigma_{u}, \mathrm{MPa}$ & $85.3[39]$ \\
\hline$d_{0}, \mathrm{~mm}$ & $0.096(4)$ \\
\hline
\end{tabular}


The predicted critical load was calculated from the following condition:

$$
\frac{\bar{R}_{\sigma}}{\sigma}=\frac{D_{c}}{\sigma_{k}},
$$

where $\sigma=F_{c} /(w g)=1 \mathrm{Mpa}-$ load applied in FEM models, at which stresses at critical distance were determined;

$\sigma_{k}=F_{k} /(w g)-$ load at which theoretically the initiation of the fracture process should occur;

$D_{c}$ - critical stress (for $\mathrm{LM}-D_{c}=\sigma_{o}$, for the Novozhilov criterion $-D_{c}=\sigma_{u}$ ),

$R_{\sigma}$ - averaged stress determined (by FEM) at the critical distance.

In the case of the LM criterion, corresponds to the principal stress $\left(R_{\sigma}=\bar{\sigma}_{I}\left(2 L, \varphi_{0}\right)\right)$. In the Novozhilov criterion, the hoop $\left(R_{\sigma}=\bar{\sigma}_{\varphi}\left(d_{0}, \varphi_{0}\right)\right)$ is used.

Formulas (6) can be transformed into a form that allows determining a theoretical damage load (stress) $\sigma_{k}(7)$ :

$$
\sigma_{k}=\frac{\sigma}{\bar{R}_{\sigma}} D_{c}
$$

Or the force at which the fracture process will be initiated (8):

$$
F_{c}=\frac{D_{c} F}{\bar{R}_{\sigma}} .
$$

The values of the critical forces $F c$ obtained from the experimental tests and tested hypotheses are presented in Table 3.

Table 3

Values of critical forces $F \boldsymbol{c}$ obtained from experimental tests (standard deviations in brackets) and tested hypotheses

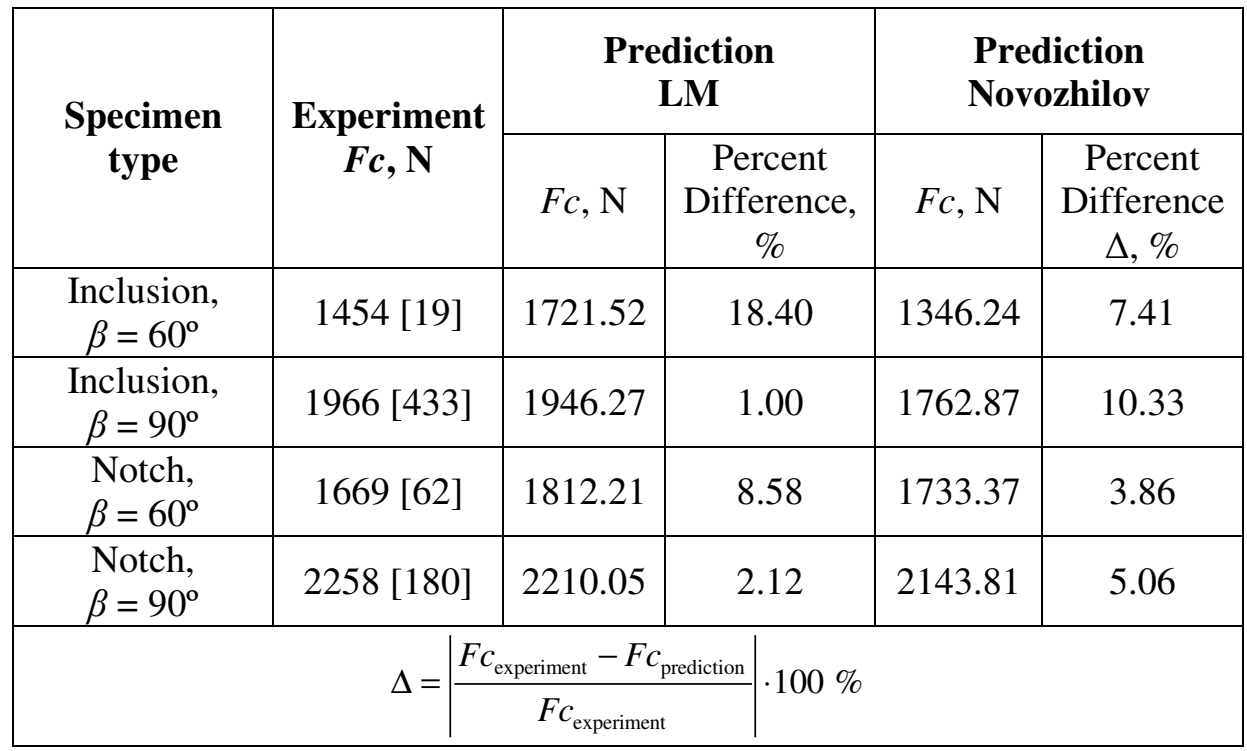

Comparing the critical forces determined using the tested hypotheses with the experimental data, it can be seen that generally better predicting accuracy is obtained using the LEFM (Novozhilov criterion) approach. Moreover, when using the classic approach (LM), the predicted damage load is greater than that determined from the Novozhilov criterion. Therefore, from a practical point of view, in the design process it is advisable to use the Novozhilov criterion for this type of element.

On the basis of the fracture criteria, crack propagation directions $\varphi_{0}$ can also be determined. The directions determined for all types of samples (the direction perpendicular to the direction of the principal stress -LM, the direction in which the hoop stress takes the maximal value - the Novozhilov criterion) were consistent with the experimental data, as shown in Figure 6. 
a)

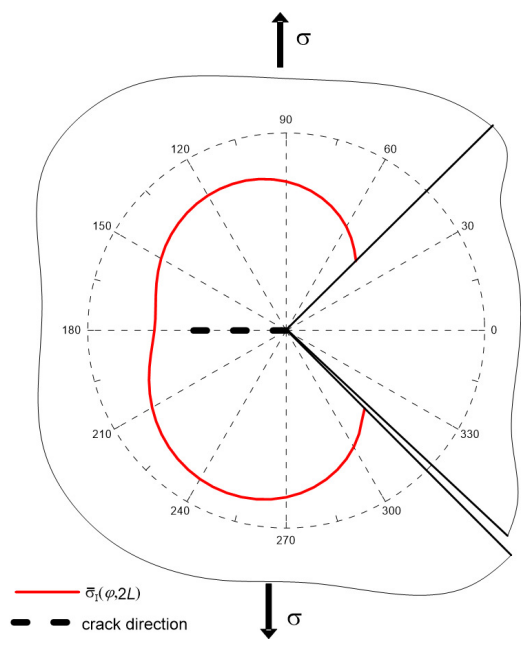

b)

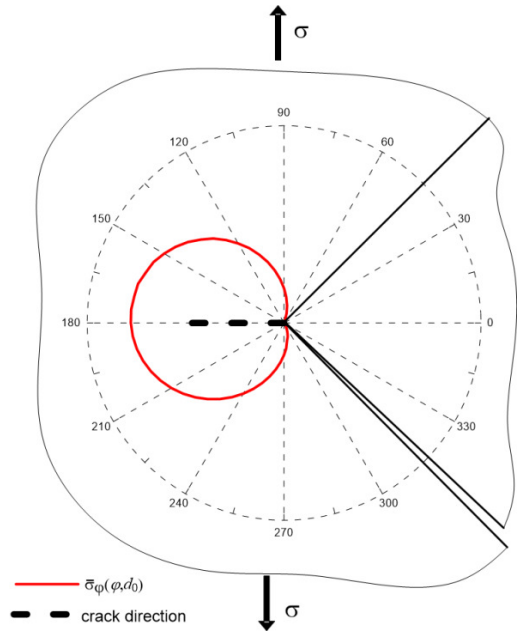

Fig. 6. Distribution of averaged stress in the tip area of inclusions:

$\mathrm{a}$ - principal stress; $\mathrm{b}$ - hoop stress, $\beta=90^{\circ}$

\section{Conclusions}

1. Comparing the values of critical forces obtained from the tested hypotheses with the experimentally determined values, it can be concluded that:

- the critical forces determined from both hypotheses coincide with the experimental data (maximum error $18.4 \%$ (specimen with inclusion, LM method), minimum error $1 \%$ (notched specimen, LM method);

- for specimens with smaller tip angles, more accurate results (7.4\% error (inclusion) and $3.86 \%$ (notch)) are obtained using the Novozhilov criterion;

- the determined critical forces with the use the Novozhilov criterion take lower values than those from the LM-based approach, therefore, this criterion should be used to predict the strength of elements with notches and inclusions;

- the directions of crack propagation, determined through both hypotheses, are consistent with the experimental data.

2. The specimens with sharp inclusions with delamination cracks were destroyed at a lower load than the notched specimens (at the same tip angle of inclusions and notches). The presence of inclusions with cracks weakens the materials more than the presence of the notch.

3. Greater accuracy in predicting fracture can be obtained, e.g., by applying a different stress than the hoop one [18] in the Novozhilov hypothesis, or by using a criterion based on the stress intensity factor [40-43]. The use of this approach to predicting critical loads (for elements with inclusions) is planned by the author.

\section{Funding:}

This publication was financed through the program of the Ministry of Science and Higher Education of Poland named "Regional Initiative of Excellence" in 2019-2022 project number 011/RID/2018/19.

\section{Acknowledgements}

This research was co-founded through the subsidy of the Ministry of Science and Higher Education for the discipline of Mechanical Engineering at the Faculty of Mechanical Engineering, Bialystok University of Technology.

\section{References}

[1] Williams M.L. The stresses around a fault or crack in dissimilar media. Bulletin of the Seismological Society of America, vol. 49, 1959, pp. 199-204.

[2] Erdogan F. Stress Distribution in a Nonhomogeneous Elastic Plane with Cracks. Journal of Applied Mechanics, vol. 30, 1963, pp. 232-236. 
[3] Rice J.R., Sih G.C. Plane Problems of Cracks in Dissimilar Media. Journal of Applied Mechanics, vol. 32, 1965, pp. 418-423.

[4] Bogy D.B. Two edge-bonded elastic wedges of different materials and wedge angles under surface tractions. Journal of Applied Mechanics, vol. 38, 1971,pp. 377-386.

[5] Mieczkowski G. Description of stress fields and displacements at the tip of a rigid, flat inclusion located at interface using modified stress intensity factors. Mechanika, vol. 21(2), 2015, pp. 9198.

[6] Mieczkowski G. Stress fields at the tip of a sharp inclusion on the interface of a bimaterial. Mechanics of Composite Materials, vol. 52(5), 2016, pp. 601-610.

[7] Mieczkowski G., Molski K., Seweryn A. Finite-element modeling of stresses and displacements near the tips of pointed inclusions. Materials Science, vol. 43( 2), 2007, pp. 183-194.

[8] Rogowski G., Molski K. The T-stress effect on the plastic zone size in a thin ductile material layer sandwiched between two elastic adherents. Engineering Fracture Mechanics, vol. 168 (A), 2016, pp. 260-270.

[9] Rogowski G. Plastic zones for 3D planar cracks embedded in an elastic-plastic layer sandwiched between two elastic adherents. Theoretical and Applied Fracture Mechanics, vol. 98, 2018, pp. 199-209.

[10] McClintock F. A. Ductile fracture instability in shear. Journal of Applied Mechanics, vol. 25, 1958, pp. 582-588.

[11] Taylor D. The Theory of Critical Distances: A new perspective in fracture mechanics. Oxford: Elsevier, 2007. 306p.

[12] Paimushin V.N., Kholmogorov S.A., Makarov M.V., Tarlakovskii D.V., Lukaszewicz A. Mechanics of fiber composites: Forms of loss of stability and fracture of test specimens resulting from three-point bending tests. ZAMM - Journal of Applied Mathematics and Mechanics / Zeitschrift für Angewandte Mathematik und Mechanik, vol. 99(1), 2019, e201800063.

[13] Sih G.C. Strain-energy-density factor applied to mixed mode crack problems. International Journal of Fracture, vol. 10, 1974, pp.305-321.

[14] Carpinteri A., Pugno N. Fracture instability and limit strength condition in structures with reentrant corners. Engineering Fracture Mechanics, vol. 72, 2005, pp.1254-1267.

[15] Kinloch A.J., Shaw,S.J., Hunston, D.L. Deformation and fracture behaviour of a rubbertoughened epoxy: 2. Failure criteria. Polymer, vol. 24(10), 1983, pp.1355-1363.

[16]Peron M., Razavi S., Torgersen J., Berto F. Fracture Assessment of PEEK under Static Loading by Means of the Local Strain Energy Density. Materials, vol. 10 (12), 2017, 1423, 10p.

[17] Peron M., Razavi S.M.J., Berto F., Torgersen J., Marsavina L. Local strain energy density for the fracture assessment of polyurethane specimens weakened by notches of different shape. Frattura ed Integrità Strutturale, vol. 11(42), 2017, pp.24-222.

[18] Mieczkowski G. Stress fields and fracture prediction for adhesively bonded bi-material structure with sharp notch located on the interface. Mechanics of Composite Materials, vol. 53(3), 2017, pp. 305-320.

[19] Neuber H. Theory of Notch Stresses: Principles for Exact Calculation of Strength with Reference to Structural form and Material. Berlin: Springer, 1958, 293p.

[20] Peterson R.E. "Notch sensitivity" In: G. Sines and J. L. Waisman, Eds., Metal Fatigue, McGrawHill, New York, 1959, pp. 293-306.

[21] Cicero A.S., Madrazo V., Carrascal I.A. 2012. Analysis of notch effect in PMMA using the Theory of Critical Distances, Engineering Fracture Mechanics, vol. 86, 2012, pp. 56-72.

[22] Whitney J.M., Nuismer, R.J. Stress fracture criteria for laminated composites containing stress concentrations. Journal of Composite Materials, vol. 8(3), 1974, pp. 253-265.

[23] Hitchen S.A., Ogin S.L., Smith P.A. Soutis C. The effect of fibre length on fracture toughness and notched strength of short carbon fibre/epoxy composites. Composites, vol. 25, 1994, pp. 407-413.

[24]Peron M., Torgersen J., Berto F. Rupture Predictions of Notched Ti-6Al-4V Using Local Approaches. Materials, vol. 11, 2018, 663, 12p.

[25]Zienkiewicz O., Taylor Ro., Zhu J.Z. 2013, The Finite Element Method: Its Basis and Fundamentals. Oxford: Butterworth-Heinemann, 2013, 756p.

[26] Mieczkowski G., Borawski A., Szpica D. Static electromechanical characteristic of a three-layer circular piezoelectric transducer, Sensors, vol. 20, 2020, 222, 14p. 
[27] Szpica D. Investigating fuel dosage non-repeatability of low pressure gas-phase injectors. Flow Measurement and Instrumentation, vol. 59, 2018, pp. 147-156.

[28] Szpica D. Simplified numerical simulation as the base for throttle flow characteristics designation. Mechanika, vol. 21(2), pp. 129-133;

[29] Szpica D. Modeling of the operation of a Dual Mass Flywheel (DMF) for different engine-related distortions. Mathematical and Computer Modelling of Dynamical Systems, vol. 24(6), 2018, pp. 643-660.

[30] Borawski A. Suggested Research Method for Testing Selected Tribological Properties of Friction Components in Vehicle Braking Systems. Acta Mechanica et Automatica, vol. 10(3), 2016, pp. 223-226.

[31] Borawski A. Common methods in analysing the tribological properties of brake pads and discs - a review. Acta Mechanica et Automatica, vol. 13(3), 2019, pp. 189-199.

[32] Borawski A. Simulation Study of the Process of Friction in the Working Elements of a Car Braking System at Different Degrees of Wear. Acta Mechanica et Automatica, vol. 12(3), 2018, pp. 221-226.

[33] Mieczkowski G. Static electromechanical characteristics of piezoelectric converters with various thickness and length of piezoelectric layers. Acta Mechanica et Automatica, vol.13(1), 2019, pp. 30-36.

[34] Eukaszewicz A. Temperature field in the contact zone in the course of rotary friction welding of metals, Materials Science, vol. 55 (1), 2019, pp. 39-45.

[35] Łukaszewicz A., Panas K., Szczebiot R. Design process of technological line to vegetables packaging using CAx tools, Proceedings of 17th International Scientific Conference on Engineering for Rural Development, May 23-25, 2018, Jelgava, Latvia, pp. 871-876.

[36] Gomez F.J., Elices M., Valiente A. Cracking in PMMA containing U-shaped notches. Fatigue and Fracture of Engineering Materials and Structures, vol. 23, 2000, pp.795-803.

[37] Novozhilov V. V. On necessary and sufficient criterion of brittle fracture, Prikladnaya Matematika i Mekhanika, vol. 33, 1969, pp. 212-222 (in Russian).

[38] Tada H., Paris P. C., Irwin G. R. The Stress Analysis of Cracks Handbook. New York: ASME Press, 2000, 698p.

[39] Lerch B. A., Thesken J. C., Bunnell C. T. Polymethylmethacrylate (PMMA) Material Test Results for the Capillary Flow Experiments (CFE), NASA/TM-2007-214835.

[40] Mieczkowski G. Criterion for crack initiation from notch located at the interface of bi-material structure. Eksploatacja i Niezawodnosc -Maintenance and Reliability, vol. 21 (2), 2019, pp. 301310.

[41] Mieczkowski G. Optimization and Prediction of Durability and Utility Features of Three-Layer Piezoelectric Transducers. Mechanika vol. 24(3), 2018, pp. 335-342.

[42] Wei Dong W., Wu Z., Tang X., Zhou X., A comparative study on stress intensity factor-based criteria for the prediction of mixed mode I-II crack propagation in concrete Engineering Fracture Mechanics, vol. 197, 2018, pp.217-235.

[43] Lesiuk G., Kucharski P., Correia J.A.F.O.,Jesus A.M.P.D, Rebeloc C., da Silvac L.S. Mixed mode (I + II) fatigue crack growth in puddle iron, Engineering Fracture Mechanics, vol. 185, 2017, pp. $175-192$. 